\title{
Interleukin-1 $\beta$-Induced Changes in Blood-Brain Barrier Permeability, Apparent Diffusion Coefficient, and Cerebral Blood Volume in the Rat Brain: A Magnetic Resonance Study
}

\author{
A. M. Blamire, ${ }^{1}$ D. C. Anthony, ${ }^{2}$ B. Rajagopalan, ${ }^{1}$ N. R. Sibson, ${ }^{1}$ V. H. Perry, ${ }^{2}$ and P. Styles ${ }^{1}$ \\ ${ }^{1}$ Medical Research Council Biochemical and Clinical Magnetic Resonance Unit, Department of Biochemistry, University of \\ Oxford, Oxford OX1 3QU, United Kingdom, and ${ }^{2} \mathrm{CNS}$ Inflammation Group, School of Biological Sciences, University of \\ Southampton, Southampton SO16 7PX, United Kingdom
}

\begin{abstract}
The cytokine interleukin-1 $\beta$ (IL-1 $\beta$ ) is implicated in a broad spectrum of CNS pathologies, in which it is thought to exacerbate neuronal loss. Here, the effects of injecting recombinant rat IL-1 $\beta$ into the striatum of 3-week-old rats were followed noninvasively from 2 to $123 \mathrm{hr}$ using magnetic resonance imaging and spectroscopy. Four hours after injection of IL-1 $\beta$ (1 ng in $1 \mu \mathrm{l})$, cerebral blood volume was significantly increased, the blood-brain barrier (BBB) became permeable to intravenously administered contrast agent between 4.5 and $5 \mathrm{hr}$, and the apparent diffusion coefficient (ADC) of brain water fell by $6 \mathrm{hr}\left(5.42 \pm 0.35 \times 10^{-4} \mathrm{~mm}^{2} / \mathrm{sec}\right.$ treated, $7.35 \pm 0.77 \times 10^{-4} \mathrm{~mm}^{2} / \mathrm{sec}$ control; $\left.p<0.001\right)$. At 24 $\mathrm{hr}$ the BBB was again intact, but the ADC, although partially recovered, remained depressed at both 24 and $123 \mathrm{hr}(p<0.03)$. Depleting the animals of neutrophils before IL- $1 \beta$ injection prevented the BBB permeability at all time points, but the ADC was still depressed at $6 \mathrm{hr}\left(6.64 \pm 0.34 \times 10^{-4} \mathrm{~mm}^{2} / \mathrm{sec}\right.$ treated,
\end{abstract}

$7.49 \pm 0.38 \times 10^{-4} \mathrm{~mm}^{2} / \mathrm{sec}$ control; $\left.p<0.005\right)$. No changes were seen in brain metabolites using proton spectroscopy at $6 \mathrm{hr}$ after IL-1 $\beta$.

Intraparenchymal injection of IL-1 $\beta$ caused a neutrophildependent transient increase in BBB permeability. The presence of neutrophils within the brain parenchyma significantly contributed to the IL- $1 \beta$-induced changes in cerebral blood volume and the ADC of brain water. However, IL-1 $\beta$ apparently had a direct effect on the resident cell populations, which persisted well after all recruited leukocytes had disappeared. Thus the action of $\mathrm{IL}-1 \beta$ alone can give rise to magnetic resonance imaging-visible changes that are normally attributed to alterations to cellular homeostasis.

Key words: interleukin-1 $\beta$; magnetic resonance; diffusion; cerebral blood volume; neutrophil; depletion
Inflammation, mediated by the action of cytokines, is a contributing factor in many diseases of the brain, including multiple sclerosis, acute neurological diseases such as stroke and head trauma, and chronic neurodegenerative diseases such as Alzheimer's disease, prion disease, and HIV-related dementia (Thomas, 1992; Betmouni et al., 1996; Rogers et al., 1996; McGeer and McGeer, 1997). Of all the cytokines, interleukin- $1 \beta$ (IL- $1 \beta$ ) has been most widely implicated as a mediator in CNS pathologies (Hauser et al., 1990; Rothwell et al., 1997). In multiple sclerosis, the level of IL-1 $\beta$ in the CSF correlates with disease activity (Hauser et al., 1990), whereas in AIDS patients, IL- $1 \beta$ is closely associated with neurodegeneration (Gendelman et al., 1994). In experimental models of focal stroke or trauma, IL-1 receptor antagonist (Stroemer and Rothwell, 1997; Sanderson et al., 1999) or interleukin-converting enzyme inhibitors (Hara et al., 1997) reduce neuronal cell death. Thus there is considerable evidence to suggest that the action of IL- $1 \beta$ in brain injury and disease is detrimental.

Magnetic resonance imaging (MRI) and magnetic resonance spectroscopy (MRS) are used in the clinical evaluation of many brain diseases in which inflammation is implicated. Conventional MRI provides a sensitive measure of tissue structure and water content and, through the use of intravenous contrast agents, can also measure blood-brain barrier (BBB) permeability (Runge et al., 1985) and cerebral perfusion (Rosen et al., 1990). Diffusionweighted MRI (DWI) acutely detects ischemic changes believed to be associated with disrupted cellular homeostasis (Mintorovitch et

Received April 6, 2000; revised Aug. 9, 2000; accepted Aug. 10, 2000.

This work was supported by the Medical Research Council (MRC) under the MRC-funded co-operative entitled The Host Response to Acute Brain Injury.

Correspondence should be addressed to Dr. Andrew M. Blamire, Medical Research Council, Magnetic Resonance Spectroscopy Unit, John Radcliffe Hospital, Headington, Oxford OX3 9DU, UK. E-mail: amb@bioch.ox.ac.uk.

Copyright (C) 2000 Society for Neuroscience $0270-6474 / 00 / 218153-07 \$ 15.00 / 0$ al., 1991; Minematsu et al., 1992b; van Bruggen et al., 1992). DW I also shows changes during experimental spreading depression (Latour et al., 1994), demonstrating a sensitivity to reversible alterations in cellular physiology, which may not be detected by subsequent histological analysis. MRS provides information on brain metabolites such as $N$-acetyl-aspartate (NAA, a compound whose loss appears linked to cellular dysfunction) and lactate production in ischemic tissue. These noninvasive techniques are, therefore, ideally suited to the temporal evaluation of models of brain disease. Furthermore, the study of specific disease models can improve our understanding of the processes leading to the MRI changes observed in clinical disease.

Previously we have examined the histological changes that occur after a single bolus injection of IL- $1 \beta$ into the brain. In juvenile animals the response is characterized by acute recruitment of neutrophils to the brain parenchyma and breakdown of the BBB, whereas in adult animals no such changes were observed (Anthony et al., 1997, 1998a). Furthermore, our single bolus injections of IL-1 $\beta$ did not appear to cause any overt damage to neurons when assessed histopathologically. Here we exploit the sensitivity of magnetic resonance imaging and spectroscopy to further evaluate the response of the juvenile brain to the injection of IL- $1 \beta$ in the presence and absence of circulating white cells to determine their contribution to the inflammatory changes. This study provides information relevant to both the understanding of the action of IL- $1 \beta$ and the identification of inflammatory processes in clinical application of MRI.

\section{MATERIALS AND METHODS}

\section{IL-1 $\beta$ solution}

Recombinant rat IL- $1 \beta$ was obtained from the National Institute for Biological Standards and Control (Potters Bar, UK). A solution of IL- $1 \beta$ was prepared using endotoxin-free saline and low-endotoxin BSA with a concentration of $1 \mathrm{ng} / \mu \mathrm{l}$. Analysis of the total endotoxin content of the carrier solution showed it to contain $<0.05 \mathrm{pg} / \mu \mathrm{l}$. 


\section{Animal preparation}

Three-week-old Wistar rats (Harlan-Olac) were anesthetized with Avertin $(1 \mathrm{ml} / 100 \mathrm{gm})$ and placed in a stereotaxic frame. A burr hole was made in the skull $1 \mathrm{~mm}$ anterior and $3 \mathrm{~mm}$ lateral to the bregma in the left hemisphere. Using a 50- $\mu$ m-tipped, finely drawn glass pipette, a $1 \mu$ injection of the IL $-1 \beta$ solution $(1 \mathrm{ng} / \mu \mathrm{l})$ was placed at a depth of $3 \mathrm{~mm}$ in the striatum. Control animals were injected with carrier only.

Animals were then placed in a purpose-built head restraint system consisting of ear and tooth bars integral to the MR coil. A 2.4-cm-diameter circular surface coil was placed over each animal's head and was used for all data acquisition. Anesthesia was maintained in the magnet using Entonox $\left(50 \% \mathrm{~N}_{2} \mathrm{O}\right.$ and $\left.50 \% \mathrm{O}_{2}\right)$ and $0.8-1.0 \%$ halothane administered via a nose cone placed around the snout of the animals. The temperature inside the probe was maintained using a circulating warm water system. All procedures used in the study were approved by the United Kingdom Home Office.

\section{Magnetic resonance methods}

Magnetic resonance measurements were made using a $300 \mathrm{MHz}$ vertical super-wide-bore spectrometer. Initial data were acquired using a Bruker Biospec console (Bruker/ORS, Coventry, UK), whereas later measurements were made using a Varian (Palo Alto, CA) Inova console because of a hardware upgrade of the spectrometer. To preserve compatibility of data throughout the study, all imaging and spectroscopy parameters were identical on both systems. Imaging and spectroscopy parameters were as follows.

Anatomical imaging. Anatomical images were acquired using a single spin-echo sequence. $\mathrm{T}_{1}$ - weighted images used a repetition time (TR) of $500 \mathrm{msec}$ and an echo time (TE) of $44 \mathrm{msec}$, whereas $\mathrm{T}_{2}$-weighted images used a TR of $2.7 \mathrm{sec}$ and a TE of $80 \mathrm{msec}$. Slice thickness was $3 \mathrm{~mm}$, field of view was $3 \times 3 \mathrm{~cm}^{2}$, and matrix size was $128 \times 128$ pixels (nominal in-plane resolution, $0.23 \times 0.23 \mathrm{~mm}^{2}$ )

$D W I$. Diffusion-weighted images were acquired with a pulsed-gradient spin-echo sequence with a TR of $1.1 \mathrm{sec}$ and a TE of $96 \mathrm{msec}$. Imaging was performed using five diff usion-weighting (" $b$ ") values of $125,500,750$ 1000 , and $1500 \mathrm{sec} / \mathrm{mm}^{-2}$, where $b$ is defined by the equation (Stejskal and Tanner, 1963) $b=(\gamma G \delta)^{2}[\Delta-\delta / 3] ; G$ is diffusion gradient strength, diffusion time $\Delta$ was $41 \mathrm{msec}$, and the diff usion gradient duration $\delta$ was 35 msec). Diffusion gradients were applied simultaneously on all three axes, and "trace" diff usion measurements were not made. Slice thickness was 3 $\mathrm{mm}$, field of view was $3 \times 3 \mathrm{~cm}^{2}$, and the matrix size was $128 \times 128$ pixels.

Imaging $B B B$ permeability. To assess BBB permeability, $150 \mu \mathrm{l}$ of a standard gadolinium-based MRI contrast agent (Omniscan; Nycomed Amersham, Buckinghamshire, UK) was injected via a tail vein, and $T_{1}$ weighted images were acquired $10 \mathrm{~min}$ after contrast administration to look for image enhancement.

Perfusion imaging. Regional cerebral blood volume (rCBV) maps were generated from time series images acquired during bolus injection of contrast agent and tracer kinetic analysis (Rosen et al., 1990). A series of 40 fast low angle shot (Frahm et al., 1986) images were acquired at a rate of 1 image/sec during which $100 \mu \mathrm{l}$ of a 50:50 solution of a Omniscan in saline was injected (TR, $20 \mathrm{msec}$; TE, $10 \mathrm{msec}$; field of view, $3 \times 2 \mathrm{~cm}^{2}$; and slice thickness, $0.5-1.0 \mathrm{~mm}$ ).

Proton MR spectroscopy. Spectra were obtained from a single $5 \times 4 \times 4$ $\mathrm{mm}^{3}$ voxel placed within the striatum of the injected hemisphere. Data were acquired using a stimulated echo acquisition mode sequence (Frahm et al., 1987) with a TE of $40 \mathrm{msec}$, a mixing time (TM) of $50 \mathrm{msec}$, a TR of $3 \mathrm{sec}$, and 128 averages. Suppression of the water signal was achieved using an inversion recovery technique (water-eliminated Fourier transform; Patt and Sykes, 1972) and a chemical shift-selective pulse (Haase et al., 1985) during the TM period.

\section{Experimental protocol}

Animals were placed in the magnet, and a sagittal scout image was acquired from which the location of the bregma was determined. The injection site was located from its stereotaxic coordinates on sagittal and coronal images. A single axial slice centered on the injection site was selected for the full imaging protocol, and a scout image was obtained. In those animals studied using MRS, the voxel of interest was positioned in the injected striatum, and the magnetic field within this region was shimmed to maximize the quality of the final spectra. Five sets of studies were performed to investigate different aspects of the brain response to IL-1 $\beta$ :

Acute effects of $I L-1 \beta(\mathrm{n}=7)$. Anatomical imaging, diffusion-weighted imaging, and spectroscopy data sets were acquired at mean time points of $3,4,5$, and $6 \mathrm{hr}$ after IL-1 $\beta$ injection. After the $6 \mathrm{hr}$ data acquisitions, postcontrast images were acquired to assess BBB permeability.

Chronic effects of $I L-1 \beta(\mathrm{n}=4)$. To examine the chronic effects of IL $-1 \beta$, a second group of animals was studied using the acute protocol described above; however, after $6 \mathrm{hr}$ the animals were allowed to recover from anesthesia and were then restudied at 27 and $123 \mathrm{hr}$ after injection. (MRS measurements were not made at 27 or $123 \mathrm{hr}$ ).

The acute effect of $I L-1 \beta$ on blood-brain barrier permeability. The temporal evolution of permeability of the BBB was studied by amalgamating the post-contrast data from protocols described above for acute and chronic effects of IL- $1 \beta$ and supplementing them with additional data acquired at 2, 3, 4, and $5 \mathrm{hr}$ time points $(n=5)$, in which imaging consisted of precontrast and postcontrast $\mathrm{T}_{1}$-weighted scans only.

Effect of neutrophil depletion $(\mathrm{n}=4)$. Neutrophils have been shown to have a direct action on the blood-brain barrier (Bolton et al., 1998). A rabbit anti-rat, anti-neutrophil serum was therefore obtained (Accurate Chemical \& Scientific) to study the effects of neutrophil depletion. Eighteen hours before IL-1 $\beta$ injection, animals were treated with an intraperitoneal injection $(3 \mathrm{ml} / \mathrm{kg})$ of the anti-neutrophil serum. Treatment with this serum typically reduces the levels of circulating neutrophils from $\sim 1800$ to $\sim 90 / \mathrm{mm}^{3}$ but has no effect on the concentration of other circulating leukocyte populations. A second injection was administered immediately before the stereotaxic surgery to ensure continued depletion. Neutrophil-depleted animals were studied $6 \mathrm{hr}$ after IL-1 $\beta$ injection using the imaging protocol and Gd contrast agent injection (as in Acute effects of IL-1 $\beta$ above). Second and third groups of animals were studied at 25 and $120 \mathrm{hr}$ time points, respectively.

Effect of IL-1 $\beta$ and neutrophils on cerebral blood volume. To determine whether IL- $1 \beta$ and recruited neutrophils exert vascular effects, cerebral blood volume was measured at 2 and $4 \mathrm{hr}$ after IL- $1 \beta$ injection in control $(n=4)$, nondepleted $(n=4)$, and neutrophil-depleted $(n=3)$ animals. Measurements were not made beyond $4 \mathrm{hr}$, because the tracer kinetic approach is not valid when contrast agent can escape from the vasculature through a permeable BBB.

\section{Histological analysis}

At the end of each protocol the rats were deeply anesthetized with sodium pentobarbitone. Transcardiac perfusions were performed with $4 \%$ paraformaldehyde. After dissection, the brains were post-fixed for several hours in the fixative and then immersed in $30 \%$ sucrose buffer for $24 \mathrm{hr}$ to cryoprotect. The tissue was then embedded in Tissue Tek (Miles, Elkhart, IN) and frozen in isopentane at $-40^{\circ} \mathrm{C}$. Cresyl violet-stained sections (50 $\mu \mathrm{m})$ were examined for signs of neuronal damage and for the presence of leukocytes. Immunohistochemistry was used to confirm the presence and distribution of specific cell populations. Frozen $10-\mu \mathrm{m}$-thick serial sections were cut from the paraformaldehyde-fixed tissue and mounted on gelatincoated glass slides. Antigens were detected using a three-step indirect method (Hsu et al., 1981). Neutrophils were identified using the antineutrophil serum HB199 (Anthony et al., 1998b).

\section{Quantification of leukocyte numbers}

In each subgroup of animals, neutrophil infiltration was quantified by counting the number of cells in 50 - $\mu \mathrm{m}$-thick cresyl violet-stained sections from regions immediately adjacent to the injection site. Three nonoverlapping fields, containing the highest density of recruited cells within the parenchyma, were chosen, and the number of neutrophils was calculated as an average number per square millimeter for each animal. All these counts were verified immunohistochemically.

\section{Magnetic resonance data analysis}

Images of the ADC were generated from the diffusion-weighted images (Turner et al., 1990). Maps of rCBV were created using standard tracer kinetic analysis of the time series data sets (Meier and Zierler, 1954; Rosen et al., 1990). Regions of interest (ROIs) encompassing the striatum were defined interactively on the $\mathrm{T}_{1}$ - and $\mathrm{T}_{2}$-weighted images in each hemisphere. These ROIs were then used to determine the mean ADC within each striatum or the ratio of rCBV in the injected to the uninjected hemisphere in individual animals. The relationship between rCBV as measured using this technique and regional cerebral blood flow (rCBF) is only indirect via the mean transit time of the tracer through the vascular bed. However, it has been shown in ischemia models that the peak signal change during the bolus correlates with autoradiographic measures of rCBF (Muller et al., 1996). The time course of signal change during the bolus passage through the brain was therefore also calculated for each region of interest to examine any differences in temporal characteristics. Anatomical images ( $\mathrm{T}_{1}$ - and $\mathrm{T}_{2}$-weighted) were assessed qualitatively for signs of signal change. BBB permeability was assessed by comparing the precontrast and postcontrast $\mathrm{T}_{1}$-weighted images. Asymmetry in image intensity within the defined ROIs was also examined to look for progressive changes. Proton spectra were line-broadened by $10 \mathrm{~Hz}$, zero-filled, and Fourier-transformed. Relative concentrations of creatine (Cre), choline (Cho), NAA, and lactate were determined by Lorentzian deconvolution of spectral lines (WIN-NMR software; Bruker-Franzen Analytik GmbH, Bremen, Germany). Spectral ratios [NAA/Cre, Cre/Cho, and NAA/(Cre + Cho)] were calculated using the creatine peak as an internal concentration reference assuming that the creatine peak was constant throughout the study. Statistical analysis was performed using $t$ test analysis. All values are quoted as mean $\pm \mathrm{SD}$.

\section{RESULTS}

\section{Acute effects of IL-1 $\beta$}

Anatomical images ( $\mathrm{T}_{1}$ - and $\mathrm{T}_{2}$-weighted) did not show any effects of injecting IL- $1 \beta$ into the striatum except on the initial images, which occasionally showed a small region of hyperintensity $(\sim 0.5$ $\mathrm{mm}$ diameter) at the site of injection, probably representing the 

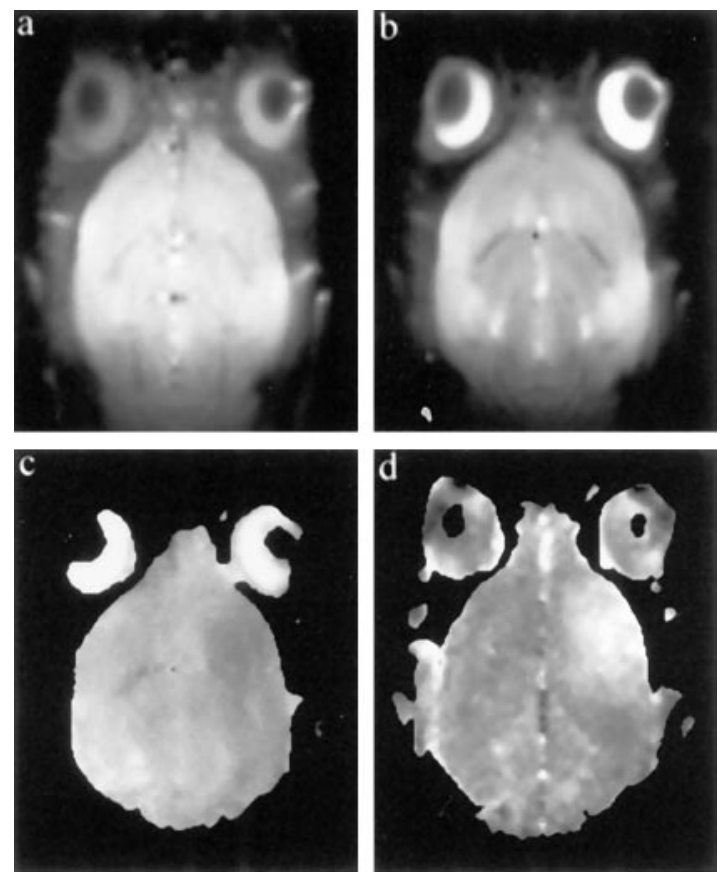

Figure 1. Typical imaging data set acquired $6 \mathrm{hr}$ after injection of IL-1 $\beta$. $a, \mathrm{~T}_{1}$-weighted axial image; $b, \mathrm{~T}_{2}$-weighted axial image; $c$, ADC map calculated from the diff usion-weighted images; $d$, image showing the area of BBB breakdown (bright) obtained by dividing the $10 \mathrm{~min}$ postcontrast $\mathrm{T}_{1}$-weighted image by the preinjection image. IL $-1 \beta$ injection was into the left hemisphere (top in each image). Note the focal area of decreased ADC, which corresponds to the area of BBB breakdown. Images are in radiological representation with the left side being the right side of the brain and vice versa.

volume of fluid injected into the brain. Similar areas of hyperintensity were seen in the control animals injected with $1 \mu$ l of vehicle solution. This hyperintensity resolved by $4 \mathrm{hr}$. Typical $\mathrm{T}_{1^{-}}$and $\mathrm{T}_{2}$-weighted anatomical images acquired $6 \mathrm{hr}$ after injection are shown in Figure 1, $a$ and $b$, respectively. The corresponding ADC map is shown in Figure 1c, whereas Figure 1d illustrates the area of postcontrast enhancement on $\mathrm{T}_{1}$-weighted imaging. These demonstrate a clear area of decreased diffusion (low intensity) in the injected striatum and extensive BBB breakdown indicated by the enhancement of the treated hemisphere. In all animals, there was a striking spatial correspondence between the area with BBB disruption on the post-Gd $\mathrm{T}_{1}$-weighted image and the area of reduced ADC. Gadolinium enhancement was clearly seen in all animals at the $6 \mathrm{hr}$ time point. ROI analysis comparing the ADC in the striatum of the treated (left) and contralateral (right) hemispheres is shown in Figure 2. The temporal evolution of the ADC demonstrated a gradual decline in the treated hemisphere, whereas the ADC in the control hemisphere remained unchanged. Throughout the study there was a trend toward lower absolute ADC values in the treated striatum compared with the control hemisphere (Table 1). Paired $t$ test (treated vs control hemisphere) at each time point showed that the difference became significant at $6 \mathrm{hr}(p<0.001)$. No ADC changes or alterations in BBB permeability were seen at any time in the control animals. Initial ratios of metabolites in the proton spectra were $1.18 \pm 0.17$ for NAA/Cre, $0.95 \pm 0.18$ for Cre/Cho, and $0.57 \pm 0.11$ for NAA/(Cre + Cho $)$ at the $3 \mathrm{hr}$ time point, and these remained unchanged throughout the acute phase of the study (3-6 hr). No lactate was observed in any spectrum. Histology confirmed the previous observations that there was infiltration of neutrophils (Anthony et al., 1997) with an average density in the quantified fields of $2024 \pm 368$ neutrophils $/ \mathrm{mm}^{2}$ $(n=3)$.

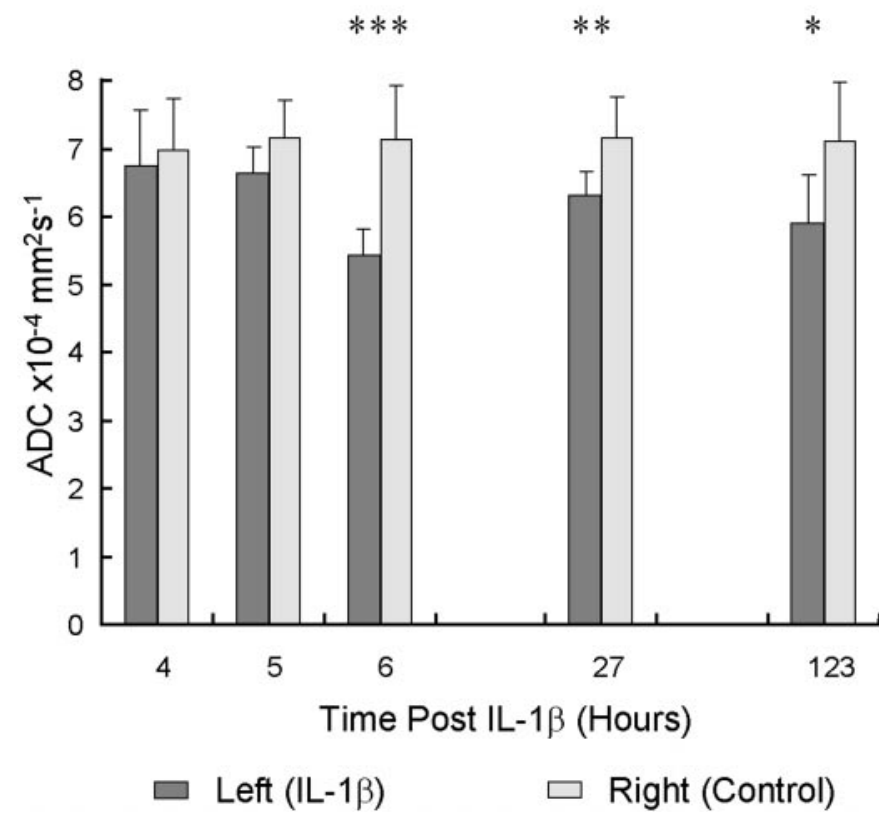

Figure 2. Time course of the ADC of brain water after striatal injection of IL-1 $\beta$. Data shown are the mean ADC (error bars indicate $1 \mathrm{SD}$ ) within a region of interest encompassing either the left (IL-1 $\beta$ treatment) or the right (control) striatum of the animals. Asterisks indicate a significant difference between treated and untreated (control) hemispheres: $* * * p<$ $0.001 ; * * p<0.01 ; * p<0.03$.

\section{Chronic effects of IL-1 $\beta$}

No regions of abnormality were seen on $\mathrm{T}_{1}$ - or $\mathrm{T}_{2}$-weighted imaging throughout the chronic phase of the study. The ADC within the treated striatum had recovered significantly by $27 \mathrm{hr}$ when compared with the $6 \mathrm{hr}$ time point (Table $1 ; p<0.001$ ) but still remained depressed relative to the contralateral hemisphere $(p<$ $0.01)$. Likewise, at $123 \mathrm{hr}$ the ADC remained significantly low $(p<$ 0.03 ) and had not increased significantly from its value at the $27 \mathrm{hr}$ time point $(p=0.4)$. Histological examination of animals after 27 hr showed neutrophil infiltration had increased to $2967 \pm 547$ neutrophils $/ \mathrm{mm}^{2}$, and neutrophils were virtually absent from the brain by $123 \mathrm{hr}\left(4 \pm 7\right.$ neutrophils $\left./ \mathrm{mm}^{2}\right)$.

\section{Effect of IL-1 $\beta$ on BBB permeability}

The acute and chronic effects of IL $-1 \beta$ on BBB permeability were assessed by amalgamating data from the anatomical imaging, DW I, and BBB permeability imaging protocols (see Materials and Methods). No image enhancement was observed at $3 \mathrm{hr}$ after IL-1 $\beta$ or earlier, and variable levels of enhancement were seen at $4 \mathrm{hr}$. However, all IL-1 $\beta$-treated animals showed clear enhancement at 5 $\mathrm{hr}$, and the effect appeared to diminish in those animals imaged at $6 \mathrm{hr}$. No enhancement was seen in any animal at $27 \mathrm{hr}$ or later, implying that the $\mathrm{BBB}$ had resealed by this time and indicating the dynamic nature of $\mathrm{BBB}$ permeability after IL- $1 \beta$ treatment.

\section{Effect of neutrophil depletion}

Histological examination of the anti-neutrophil serum-treated animals confirmed the absence of any neutrophil recruitment to the brain parenchyma or meninges. In these animals the ADC at $6 \mathrm{hr}$ after IL- $1 \beta$ injection was significantly depressed compared with the control hemisphere but to a much lesser degree than in animals with neutrophil present (Table $1 ; p<0.005$ ). This is shown in Figure 3 together with the data for control animals (injection of the carrier only). Post-Gd imaging did not show enhancement, indicating an intact BBB. In the groups of neutrophil-depleted animals studied chronically, the ADC at 25 and $120 \mathrm{hr}$ had returned to control values. 
Table 1. Apparent diffusion coefficient in the left (treated) and right (control) striatum

\begin{tabular}{|c|c|c|c|c|c|c|}
\hline \multirow[b]{3}{*}{ Time (hr) } & \multicolumn{6}{|c|}{$\operatorname{ADC}\left(\times 10^{-4} \mathrm{~mm}^{2} / \mathrm{sec}\right)$} \\
\hline & \multicolumn{2}{|l|}{ Control } & \multicolumn{2}{|l|}{$\underline{\mathrm{IL}-1 \beta}$} & \multicolumn{2}{|c|}{ Neutrophil depletion and IL $-1 \beta$} \\
\hline & Left & Right & Left & Right & Left & Right \\
\hline 4 & & & $6.74 \pm 0.82$ & $6.96 \pm 0.76$ & & \\
\hline 5 & & & $6.63 \pm 0.38$ & $7.15 \pm 0.56$ & & \\
\hline 6 & $7.30 \pm 0.25$ & $7.29 \pm 0.21$ & $5.42 \pm 0.35^{*}$ & $7.35 \pm 0.77$ & $6.64 \pm 0.34^{*}$ & $7.49 \pm 0.38$ \\
\hline 27 & & & $6.29 \pm 0.35^{*}$ & $7.14 \pm 0.61$ & $7.15 \pm 0.58$ & $7.28 \pm 0.27$ \\
\hline 123 & & & $5.90 \pm 0.70^{*}$ & $7.10 \pm 0.87$ & $7.10 \pm 0.26$ & $7.13 \pm 0.15$ \\
\hline
\end{tabular}

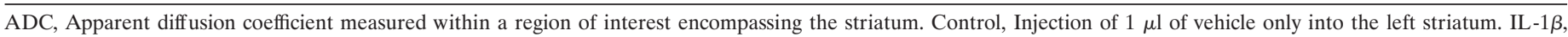

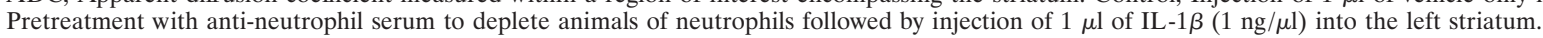

*Significantly different from control (right hemisphere) by paired $t$ test at that time point $(p<0.05)$.
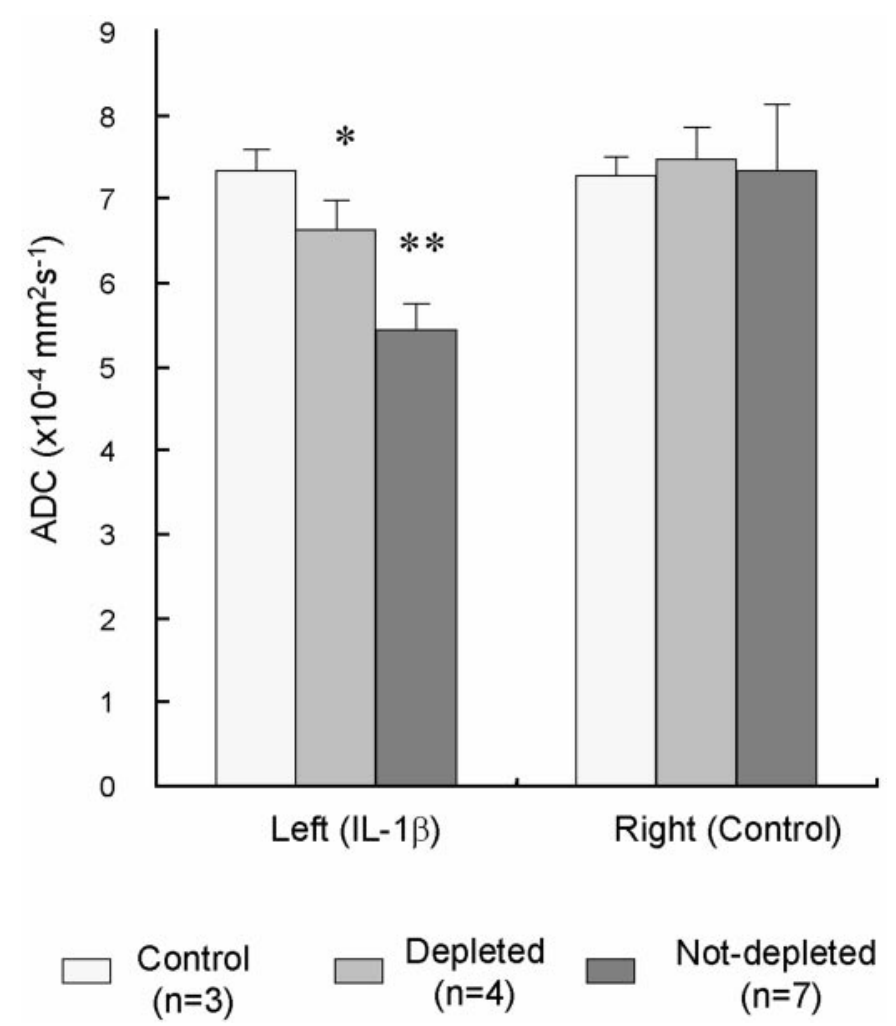

Figure 3. Comparison of the mean ADC (error bars indicate $1 \mathrm{SD}$ ) in the left and right striatum $6 \mathrm{hr}$ after IL-1 $\beta$ injection. Data are presented for the three animal groups: control (injection of vehicle only), depleted (pretreatment with anti-neutrophil serum to deplete neutrophils and then injection of IL-1 $\beta$ ), and nondepleted (IL-1 $\beta$ injection only). Asterisks indicate a significant difference between treated and untreated (control) hemispheres: $* *^{*}<0.001 ; * p<0.005$.

\section{Effect of IL-1 $\beta$ and neutrophils on cerebral blood volume}

Local changes in cerebral hemodynamics were assessed by calculating the ratio of cerebral blood volume within the ROI in the treated hemisphere to that in the control hemisphere. At $2 \mathrm{hr}$ after injection, rCBV appeared slightly (but not significantly) increased in the treated hemisphere of animals injected with IL-1 $\beta$ but not in the neutrophil-depleted animals (Fig. 4). By $4 \mathrm{hr}$ after injection, rCBV was significantly increased in the striatum of the IL- $1 \beta$ treated animals ( $p=0.004$, paired $t$ test). A trend to increased rCBV was also seen in the neutrophil-depleted animals $(p=0.08)$. The temporal characteristics of the contrast bolus were identical between the treated and untreated hemispheres. Control animals showed no asymmetry in rCBV at either 2 or $4 \mathrm{hr}$ after injection.
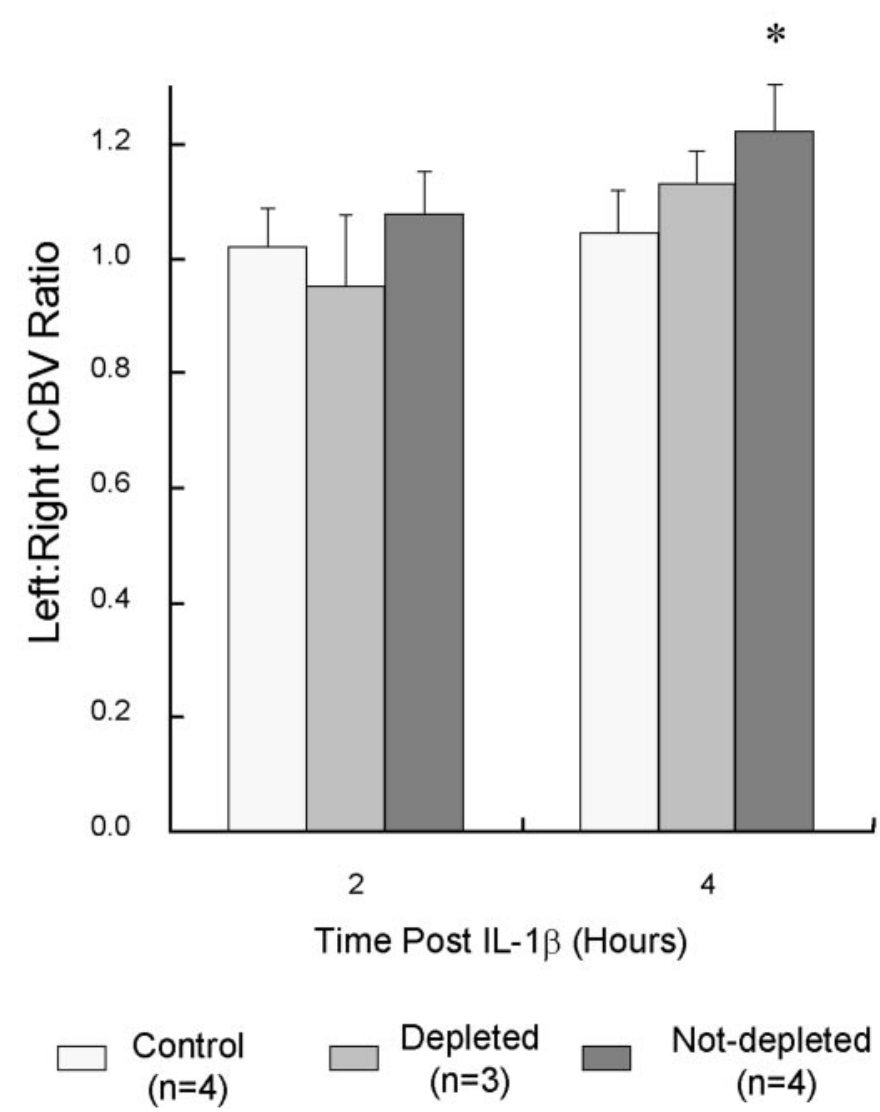

Figure 4. Comparison of the mean ratio of $\mathrm{rCBV}$ in the treated and untreated striatum at 2 and $4 \mathrm{hr}$ after injection (error bars indicate $1 \mathrm{SD}$ ). Data are presented for the three animal groups: control (injection of vehicle only), depleted (pretreatment with anti-neutrophil serum to deplete neutrophils and then injection of IL-1 $\beta$ ), and nondepleted (IL-1 $\beta$ injection only). Asterisks indicate a significant difference between treated and control hemispheres: $* p=0.004$.

\section{DISCUSSION}

In the present study, we have found that in the juvenile rat brain IL-1 $\beta$ induces (1) a neutrophil-dependent increase in the permeability of the BBB to Gd contrast agent in the absence of any signal change on conventional anatomical MR imaging, (2) a reversible decrease in the apparent diff usion coefficient with no acute changes in the level of NAA or appearance of lactate as determined by MRS, and (3) increased regional cerebral blood volume acutely. In control animals after the injection of vehicle alone, no significant changes were observed on $\mathrm{T}_{1}$ - or $\mathrm{T}_{2}$-weighted images, ADC images, or gadolinium-enhanced $\mathrm{T}_{1}$ images, and there were no blood 
volume changes. The implications of these findings are discussed below.

Trauma-induced lesions and ischemic lesions in the CNS are associated with leukocyte infiltration, BBB breakdown, and secondary tissue destruction. This study has confirmed that BBB breakdown occurs after the injection of IL- $1 \beta$, in broad agreement with our previous results obtained using horseradish peroxidase (HRP), the classic tracer of BBB permeability. Using HRP the $\mathrm{BBB}$ was found to be impermeable at $2 \mathrm{hr}$ after IL-1 $\beta$ injection and maximally open at $4 \mathrm{hr}$ (Anthony et al., 1997). Similarly, the data presented here indicate that BBB breakdown occurred between 4 and $5 \mathrm{hr}$. However, these data also show some continuing permeability at $6 \mathrm{hr}$, which was not observed with HRP and is probably attributable to the lower molecular weight of the Gd tracer. The current study with $\mathrm{Gd}$ also revealed that the increase in BBB permeability in these juvenile animals is neutrophil-dependent, because neutrophil depletion eliminated the IL- $1 \beta$-induced increases in permeability. There are opposing observations on the action of IL- $1 \beta$ on $\mathrm{BBB}$ permeability. In vitro there is a wealth of data reporting that proinflammatory cytokines, such as IL- $1 \beta$, increase the permeability of brain-derived endothelial cell monolayers (de Vries et al., 1996; Duchini et al., 1996; Fiala et al., 1997; Gloor et al., 1997). For example, in a study using cerebrovascularderived endothelial cells, IL-1 $\beta$, tumor necrosis factor $\alpha$, and IL-6 all induced a decrease in the trans-endothelial cell resistance in vitro (de Vries et al., 1996). Also, other in vivo studies using intraparenchymal injection of IL- $1 \beta$ have reported extravasation of albumin and increased specific density of tissue, both indicating increased BBB permeability (Holmin and Mathiesen, 2000). However, our previous work using this model and the tracer HRP both in juvenile and adult animals has not observed BBB breakdown in the absence of neutrophils (Anthony et al., 1997, 1998a; Schnell et al., 1999). Explanations for this disparity may lie in possible tissue damage occurring as a function of the needle size or injection volume (both of which are smaller in our work), which when combined with exogenous IL- $1 \beta$ may give rise to pathology distinct and different from the effect of IL- $1 \beta$ in the brain parenchyma per se. Alternatively it must be considered that in using the relatively large HRP molecule we may have missed any neutrophilindependent IL- $1 \beta$-induced changes in BBB permeability because of the size of the tracer $(40 \mathrm{kDa})$. The gadolinium complex used in this current study is much smaller $(0.57 \mathrm{kDa})$ and is therefore unlikely to have been excluded from the brain parenchyma even if the direct IL-1 $\beta$-induced changes were small. Therefore, our data suggest that the permeability changes in the $\mathrm{BBB}$ in vivo in juvenile rats result from the action of neutrophils rather than the proinflammatory cytokine IL- $1 \beta$ per se.

After injection of IL- $1 \beta$ into the striatum we observed a decline in the ADC, which remained significantly depressed until well after the $\mathrm{BBB}$ had been restored and the recruited leukocytes had disappeared. A reduction in ADC has been extensively documented in acute brain ischemia (Moseley et al., 1990a,b; Knight et al., 1991; Mintorovitch et al., 1991, 1994; Minematsu et al., 1992a; van Bruggen et al., 1992; Roussel et al., 1994; van der Toorn et al., 1994; Verheul et al., 1994; Kohno et al., 1995; Mancuso et al., 1997; Kuroiwa et al., 1999), although the exact mechanisms responsible for these changes remain unclear. In ischemia the ADC falls before any major changes on conventional $\mathrm{T}_{1}$ - or $\mathrm{T}_{2}$-weighted imaging and has an acute temporal evolution that appears to follow the loss of high-energy phosphorus metabolites (van der Toorn et al., 1996a). There is evidence to support the idea that diffusion in the intracellular space is much slower than in the extracellular space (Van Zijl et al., 1991). Thus in ischemia, reduced ADC may represent, in part, the formation of cytotoxic edema (leading to an increased contribution to the measured ADC from the slower-diff using intracellular water) (Verheul et al., 1994; van der Toorn et al., 1996a). There is, however, also evidence that diffusion in both the cytosol and interstitial space is altered during ischemia (Wick et al., 1995; Neil et al., 1996; van der Toorn et al., 1996b; Duong et al., 1998); therefore, reduced overall ADC may also represent changes in absolute diffusibility. Furthermore, observations of a transient reduction in ADC during spreading depression (Latour et al., 1994) suggest that the ADC does not simply report on tissue undergoing ischemia. In our study, the time course of ADC changes in the injected hemisphere only became significantly different from normal tissue after $6 \mathrm{hr}$. Again, this is in contrast to the time course in classic ischemia, in which ADC changes are virtually immediate. Perfusion imaging showed increased rCBV by $4 \mathrm{hr}$ after IL-1 $\beta$, in agreement with previous qualitative observations of intraparenchymal vessel dilation in this model (Anthony et al., 1997). The temporal characteristics of the bolus were the same between each hemisphere; hence, peak signal change scaled with rCBV. This suggests that $\mathrm{rCBF}$ is also elevated in response to IL- $1 \beta$ or action of neutrophil. Furthermore, no lactate was observed in any proton spectra, as might be expected if ischemia were an important factor. Thus, ischemia is unlikely to be the source of the ADC changes in this model.

Although BBB permeability was found to be related to the recruitment of neutrophils to the brain parenchyma and could be eliminated in neutrophil-depleted animals, a reduction in ADC still occurred in the absence of neutrophils. This indicates that IL-1 $\beta$ has a direct effect on the resident cells within the brain parenchyma. Previously we have found that the injection of IL- $1 \beta$ rapidly induces the production of more IL- $1 \beta$, and this increase in endogenous production is decreased in neutrophil-depleted animals (our unpublished observations). Interestingly, relative to animals with neutrophils, the duration and magnitude of ADC changes were both diminished in the neutrophil-depleted animals. Together these observations suggest that the ADC changes reflect the total level of IL-1 $\beta$, particularly during the acute phase after injection. However, it should also be noted that the reduction in ADC continued well after the point when neutrophils have been cleared from the parenchyma, indicating that some other currently unknown mechanism is involved, at least in the chronic phase.

IL-1 $\beta$ has been found to be neurotoxic in co-cultures of astrocytes and neurons and at high concentrations in cultured primary cortical neurons (Skaper et al., 1995; Strijbos and Rothwell, 1995). In acute in vivo studies, too, there is now evidence that inhibition of the activity of IL- $1 \beta$ by IL- 1 receptor antagonist can reduce infarct volume in rodent models of ischemia and reduce neuronal damage after brain injury by fluid percussion (Garcia et al., 1995; Toulmond and Rothwell, 1995). However, it remains unclear how IL-1 $\beta$ exacerbates focal lesions in the CNS. Exacerbation may be a result of the direct cytotoxic action of IL- $1 \beta$ on neurons or particular neuronal pathways, and there may also be secondary bystander damage by the leukocytes recruited to the brain after endogenous IL-1 $\beta$ production. Indeed, the inhibition of neutrophil recruitment in models of focal stroke has proved effective in reducing the infarct volume (Matsuo et al., 1994; Jiang et al., 1995). Our previous studies have demonstrated that single bolus injections of IL- $1 \beta$ into the brain parenchyma of juvenile animals result in the acute recruitment of neutrophils to the brain and neutrophil-mediated damage to the blood-brain barrier (Anthony et al., 1997, 1998a). Although our previous studies have suggested that single bolus injections of IL- $1 \beta$ do not appear to cause damage to neurons as assessed histopathologically with silver stains, the current ADC data suggest that some form of prolonged alteration in cellular homeostasis is produced.

We have demonstrated that IL- $1 \beta$ induces reversible BBB breakdown in juvenile animals, which is mediated by neutrophils. The ADC falls, possibly indicating cellular dysfunction as a result of both direct effects of IL- $1 \beta$ and neutrophil-mediated mechanisms. IL- $1 \beta$ also produces an increase in cerebral blood volume in the areas with $\mathrm{BBB}$ and $\mathrm{ADC}$ changes, and this increase is diminished in the absence of neutrophils. The mechanism of the ADC changes after IL- $1 \beta$ treatment may be relevant to its effects in exacerbating damage in stroke or traumatic brain injury. 


\section{REFERENCES}

Anthony D, Dempster R, Fearn S, Clements J, Wells G, Perry VH, Walker K (1998a) CXC chemokines generate age-related increases in neutrophil-mediated brain inflammation and blood-brain barrier breakdown. Curr Biol 8:923-926.

Anthony DC, Bolton SJ, Fearn S, Perry VH (1997) Age-related effects of interleukin-1 beta on polymorphonuclear neutrophil-dependent increases in blood-brain barrier permeability in rats. Brain 120:435-444.

Anthony DC, Miller KM, Fearn S, Townsend MJ, Wells GMA, Clements JM, Chandler S, Gearing AJH, Perry VH (1998b) Matrix metalloproteinase expression in an experimentally-induced DTH model of multiple sclerosis in the rat CNS. J Neuroimmunol 87:62-73.

Betmouni S, Perry VH, Gordon JL (1996) Evidence for an early inflammatory response in the central nervous system of mice with scrapie. Neuroscience 74:1-5.

Bolton SJ, Anthony DC, Perry VH (1998) Loss of the tight junction proteins occludin and zonula occludens-1 from cerebral vascular endothelium during neutrophil-induced blood-brain barrier breakdown in vivo. Neuroscience 86:1245-1257.

de Vries HE, Blom-Roosemalen MC, van Oosten M, de Boer AG, van Berkel TJ, Breimer DD, Kuiper J (1996) The influence of cytokines on the integrity of the blood-brain barrier in vitro. $\mathrm{J}$ Neuroimmunol 64:37-43.

Duchini A, Govindarajan S, Santucci M, Zampi G, Hofman FM (1996) Effects of tumor necrosis factor-alpha and interleukin-6 on fluid-phase permeability and ammonia diffusion in CNS-derived endothelial cells. J Invest Med 44:474-482.

Duong TQ, Ackerman JJ, Ying HS, Neil JJ (1998) Evaluation of extraand intracellular apparent diffusion in normal and globally ischemic rat brain via 19F NMR. Magn Reson Med 40:1-13.

Fiala M, Looney DJ, Stins M, Way DD, Zhang L, Gan X, Chiappelli F Schweitzer ES, Shapshak P, Weinand M, Graves MC, Witte M, Kim KS (1997) TNF-alpha opens a paracellular route for HIV-1 invasion across the blood-brain barrier. Mol Med 3:553-564.

Frahm J, Haase A, Matthaei D (1986) Rapid NMR imaging of dynamic processes using the FLASH technique. Magn Reson Med 3:321-327.

Frahm J, Merboldt KD, Hanicke W (1987) Localised proton spectroscopy using stimulated echoes. J Magn Reson 72:502-508.

Garcia JH, Liu KF, Relton JK (1995) Interleukin-1 receptor antagonist decreases the number of necrotic neurons in rats with middle cerebral artery occlusion. Am J Pathol 147:1477-1486.

Gendelman HE, Genis P, Jett M, Zhai QH, Nottet HS (1994) An experimental model system for HIV-1-induced brain injury. Adv Neuroimmunol 4:189-193.

Gloor SM, Weber A, Adachi N, Frei K (1997) Interleukin-1 modulates protein tyrosine phosphatase activity and permeability of brain endothelial cells. Biochem Biophys Res Commun 239:804-809.

Haase A, Frahm J, Hanicke W, Matthaei D (1985) 1H NMR chemica shift selective (CHESS) imaging. Phys Med Biol 30:341-344.

Hara H, Friedlander RM, Gagliardini V, Ayata C, Fink K, Huang Z, Shimizu-Sasamata M, Yuan J, Moskowitz MA (1997) Inhibition of interleukin 1beta converting enzyme family proteases reduces ischemic and excitotoxic neuronal damage. Proc Natl Acad Sci USA 94:2007-2012.

Hauser SL, Doolittle TH, Lincoln R, Brown RH, Dinarello CA (1990) Cytokine accumulations in CSF of multiple sclerosis patients: frequent detection of interleukin-1 and tumor necrosis factor but not interleukin-6. Neurology 40:1735-1739.

Holmin S, Mathiesen T (2000) Intracerebral administration of interleukin-1beta and induction of inflammation, apoptosis, and vasogenic edema. J Neurosurg 92:108-120.

Hsu SM, Raine L, Fanger H (1981) The use of antiavidin antibody and avidin-biotin-peroxidase complex in immunoperoxidase technics. Am J Clin Pathol 75:816-821.

Jiang N, Moyle M, Soule HR, Rote WE, Chopp M (1995) Neutrophil inhibitory factor is neuroprotective after focal ischemia in rats. Ann Neurol 38:935-942.

Knight RA, Ordidge RJ, Helpern JA, Chopp M, Rodolosi LC, Peck D (1991) Temporal evolution of ischemic damage in rat brain measured by proton nuclear magnetic resonance imaging. Stroke 22:802-808.

Kohno K, Hoehn-Berlage M, Mies G, Back T, Hossmann KA (1995) Relationship between diffusion-weighted MR images, cerebral blood flow, and energy state in experimental brain infarction. Magn Reson Imaging 13:73-80.

Kuroiwa T, Nagaoka T, Ueki M, Yamada I, Miyasaka N, Akimoto H, Ichinose S, Okeda R, Hirakawa K (1999) Correlations between the apparent diffusion coefficient, water content, and ultrastructure after induction of vasogenic brain edema in cats. J Neurosurg 90:499-503.

Latour LL, Hasegawa Y, Formato JE, Fisher M, Sotak CH (1994) Spreading waves of decreased diffusion coefficient after cortical stimulation in the rat brain. Magn Reson Med 32:189-198.

Mancuso A, Nimura T, Weinstein PR (1997) Prediction of delayed ischemic injury with diffusion-weighted MRI following temporary middle cerebral artery occlusion in rats. Brain Res 760:42-51.

Matsuo Y, Onodera H, Shiga Y, Nakamura M, Ninomiya M, Kihara T,
Kogure K (1994) Correlation between myeloperoxidase-quantified neutrophil accumulation and ischemic brain injury in the rat-effects of neutrophil depletion. Stroke 25:1469-1475.

McGeer EG, McGeer PL (1997) Inflammatory cytokines in the CNS possible role in the pathogenesis of neurodegenerative disorders and therapeutic implications. CNS Drugs 7:214-228.

Meier P, Zierler K (1954) On the theory of the indicator-dilution method for measurement of blood flow and volume. J Appl Physiol 12:731-744.

Minematsu K, Li L, Fisher M, Sotak CH, Davis MA, Fiandaca MS (1992a) Diffusion-weighted magnetic resonance imaging: rapid and quantitative detection of focal brain ischemia. Neurology 42:235-240.

Minematsu K, Li L, Sotak CH, Davis MA, Fisher M (1992b) Reversible focal ischemic injury demonstrated by diffusion-weighted magnetic resonance imaging in rats. Stroke 23:1304-1310.

Mintorovitch J, Moseley ME, Chileuitt L, Shimizu H, Cohen Y, Weinstein PR (1991) Comparison of diffusion- and T2-weighted MRI for the early detection of cerebral ischemia and reperfusion in rats. Magn Reson Med 18:39-50.

Mintorovitch J, Yang GY, Shimizu H, Kucharczyk J, Chan PH, Weinstein PR (1994) Diffusion-weighted magnetic resonance imaging of acute focal cerebral ischemia: comparison of signal intensity with changes in brain water and $\mathrm{Na}+, \mathrm{K}(+)$-ATPase activity. J Cereb Blood Flow Metab 14:332-336.

Moseley ME, Cohen Y, Mintorovitch J, Chileuitt L, Shimizu H, Kucharczyk J, Wendland MF, Weinstein PR (1990a) Early detection of regional cerebral ischemia in cats: comparison of diffusion- and T2weighted MRI and spectroscopy. Magn Reson Med 14:330-346.

Moseley ME, Kucharczyk J, Mintorovitch J, Cohen Y, Kurhanewicz J, Derugin N, Asgari H, Norman D (1990b) Diffusion-weighted MR imaging of acute stroke: correlation with T2-weighted and magnetic susceptibility-enhanced MR imaging in cats. AJNR Am J Neuroradiol 11:423-429.

Muller TB, Jones RA, Haraldseth O, Westby J, Unsgard G (1996) Comparison of MR perfusion imaging and microsphere measurements of regional cerebral blood flow in a rat model of middle cerebral artery occlusion. Magn Reson Imaging 14:1177-1183.

Neil JJ, Duong TQ, Ackerman JJ (1996) Evaluation of intracellular diffusion in normal and globally-ischemic rat brain via $133 \mathrm{Cs}$ NMR. Magn Reson Med 35:329-335.

Patt S, Sykes BD (1972) Water eliminated Fourier transform NMR spectroscopy. J Chem Phys 56:3182-3184.

Rogers J, Webster S, Lue L-F, Brachova L, Civin WH, Emmerling M, Shivers B, Wlaker D, McGeer P (1996) Inflammation and Alzheimer's disease pathology. Neurobiol Aging 17:681-686.

Rosen BR, Belliveau JW, Vevea JM, Brady TJ (1990) Perfusion imaging with NMR contrast agents. Magn Reson Med 14:249-265.

Rothwell N, Allan S, Toulmond S (1997) The role of interleukin 1 in acute neurodegeneration and stroke: pathophysiological and therapeutic implications. J Clin Invest 100:2648-2652.

Roussel SA, van Bruggen N, King MD, Houseman J, Williams SR, Gadian DG (1994) Monitoring the initial expansion of focal ischaemic changes by diffusion-weighted MRI using a remote controlled method of occlusion. NMR Biomed 7:21-28.

Runge VM, Clanton JA, Price AC, Wehr CJ, Herzer WA, Partain CL, James Jr AE (1985) The use of Gd DTPA as a perfusion agent and marker of blood-brain barrier disruption. Magn Reson Imaging 3:43-55.

Sanderson KL, Raghupathi R, Saatman KE, Martin D, Miller G, McIntosh TK (1999) Interleukin-1 receptor antagonist attenuates regional neuronal cell death and cognitive dysfunction after experimental brain injury. J Cereb Blood Flow Metab 19:1118-1125.

Schnell L, Fearn S, Schwab ME, Perry VH, Anthony DC (1999) Cytokine-induced acute inflammation in the brain and spinal cord. J Neuropathol Exp Neurol 58:245-254.

Skaper SD, Facci L, Leon A (1995) Inflammatory mediator stimulation of astrocytes and meningeal fibroblasts induces neuronal degeneration via the nitridergic pathway. J Neurochem 64:266-276.

Stejskal EO, Tanner JE (1963) Spin diffusion measurements:Spin echoes in the presence of a time-dependent field gradient. J Chem Phys 42:288-292.

Strijbos PJ, Rothwell NJ (1995) Interleukin-1 beta attenuates excitatory amino acid-induced neurodegeneration in vitro: involvement of nerve growth factor. J Neurosci 15:3468-3474.

Stroemer RP, Rothwell NJ (1997) Cortical protection by localized striatal injection of IL-1ra following cerebral ischemia in the rat. J Cereb Blood Flow Metab 17:597-604.

Thomas WE (1992) Brain macrophages: evaluation of microglia and their functions. Brain Res Rev 17:61-74.

Toulmond S, Rothwell NJ (1995) Interleukin-1 receptor antagonist inhibits neuronal damage caused by fluid percussion injury in the rat. Brain Res 671:261-266.

Turner R, Le Bihan D, Maier J, Vavrek R, Hedges LK, Pekar J (1990) Echo-planar imaging of intravoxel incoherent motion. Radiology 177: 407-414. 
van Bruggen N, Cullen BM, King MD, Doran M, Williams SR, Gadian DG, Cremer JE (1992) T2- and diffusion-weighted magnetic resonance imaging of a focal ischemic lesion in rat brain. Stroke 23:576-582.

van der Toorn A, Verheul HB, van der Sprenkel JW, Tulleken CA, Nicolay $\mathrm{K}$ (1994) Changes in metabolites and tissue water status after focal ischemia in cat brain assessed with localized proton MR spectroscopy. Magn Reson Med 32:685-691.

van der Toorn A, Sykova E, Dijkhuizen RM, Vorisek I, Vargova L, Skobisova E, van Lookeren Campagne M, Reese T, Nicolay K (1996a)

Dynamic changes in water ADC, energy metabolism, extracellular space volume, and tortuosity in neonatal rat brain during global ischemia. Magn Reson Med 36:52-60.

van der Toorn A, Dijkhuizen RM, Tulleken CA, Nicolay K (1996b) Dif- fusion of metabolites in normal and ischemic rat brain measured by localized 1H MRS. Magn Reson Med 36:914-922.

Van Zijl PC, Moonen CT, Faustino P, Pekar J, Kaplan O, Cohen JS (1991) Complete separation of intracellular and extracellular information in NMR spectra of perfused cells by diffusion-weighted spectroscopy. Proc Natl Acad Sci USA 88:3228-3232.

Verheul HB, Balazs R, Berkelbach van der Sprenkel JW, Tulleken CA, Nicolay K, Tamminga KS, van Lookeren Campagne M (1994) Comparison of diff usion-weighted MRI with changes in cell volume in a rat model of brain injury. NMR Biomed [erratum (1994) 7:374] 7:96-100.

Wick M, Nagatomo Y, Prielmeier F, Frahm J (1995) Alteration of intracellular metabolite diffusion in rat brain in vivo during ischemia and reperfusion. Stroke 26:1930-1934. 